\title{
Hypopituitarism after Gamma Knife radiosurgery for pituitary adenomas: a multicenter, international study
}

\author{
Diogo Cordeiro, MD, ${ }^{1}$ Zhiyuan Xu, MD, ${ }^{1}$ Gautam U. Mehta, MD,1 Dale Ding, MD,1 \\ Mary Lee Vance, MD, ${ }^{1}$ Hideyuki Kano, MD, PhD, ${ }^{2}$ Nathaniel Sisterson, BA, ${ }^{2}$ Huai-che Yang, MD, ${ }^{2}$ \\ Douglas Kondziolka, MD, ${ }^{2,8}$ L. Dade Lunsford, MD, PhD, ${ }^{2}$ David Mathieu, MD, ${ }^{3}$ \\ Gene H. Barnett, MD, ${ }^{4}$ Veronica Chiang, MD, PhD, ${ }^{5}$ John Lee, MD, ${ }^{6}$ Penny Sneed, MD, \\ Yan-Hua Su, MD, ${ }^{9}$ Cheng-chia Lee, MD, PhD, ${ }^{9}$ Michal Krsek, MD, ${ }^{10}$ Roman Liscak, MD, ${ }^{10}$ \\ Ahmed M. Nabeel, MD, PhD, ${ }^{11}$ Amr El-Shehaby, MD, PhD, 12,17 Khaled Abdel Karim, MD, ${ }^{12,17}$ \\ Wael A. Reda, MD, PhD, ${ }^{12,17}$ Nuria Martinez-Moreno, MD, ${ }^{13}$ Roberto Martinez-Alvarez, MD, ${ }^{13}$ \\ Kevin Blas, MD, ${ }^{14}$ Inga Grills, MD, ${ }^{14}$ Kuei C. Lee, MD, PhD, ${ }^{14}$ Mikulas Kosak, MD, PhD, ${ }^{15}$ \\ Christopher P. Cifarelli, MD, PhD, ${ }^{16}$ Gennadiy A. Katsevman, MD, ${ }^{16}$ and \\ Jason P. Sheehan, MD, PhD'
}

\begin{abstract}
'Department of Neurological Surgery, University of Virginia, Charlottesville, Virginia; 'Department of Neurological Surgery, University of Pittsburgh, Pittsburgh, Pennsylvania; ${ }^{3}$ Department of Surgery, Division of Neurosurgery, Université de Sherbrooke, Centre de recherche du CHUS, Sherbrooke, Quebec, Canada; ${ }^{4 D}$ Department of Brain Tumor and Neuro-Oncology Center, Cleveland Clinic, Cleveland, Ohio; ${ }^{5}$ Department of Neurosurgery, Yale University, New Haven, Connecticut; ${ }^{6}$ Department of Neurosurgery, University of Pennsylvania, Philadelphia, Pennsylvania; 'Department of Radiation Oncology, University of California, San Francisco, California; ${ }^{8}$ Department of Neurosurgery, New York University, New York, New York; ${ }^{9}$ Department of Neurosurgery, Neurological Institute, Taipei Veterans General Hospital, Taipei, Taiwan, Republic of China; ${ }^{10}$ Department of Stereotactic and Radiation Neurosurgery, Na Homolce Hospital, Prague, Czech Republic; "11Department of Neurosurgery, Faculty of Medicine, Benha University, Qalubya, Egypt; ${ }^{2}$ Department of Clinical Oncology and Nuclear Medicine, Faculty of Medicine, Ain Shams University, Cairo, Egypt; ${ }^{13}$ Department of Functional Neurosurgery and Radiosurgery, Ruber International Hospital, Madrid, Spain; ${ }^{14}$ Radiation Oncology Department, Beaumont Health System, Royal Oak, Michigan; ${ }^{15}$ Third Department of Medicine, Department of Endocrinology and Metabolism, First Faculty of Medicine, Charles University and General University Hospital, Prague, Czech Republic; ${ }^{16}$ Department of Neurosurgery, West Virginia University, Morgantown, West Virginia; and ${ }^{17 G a m m a ~ K n i f e ~ C e n t e r ~ C a i r o-N a s s e r ~ I n s t i t u t e, ~ N e u r o s u r g e r y ~ D e p a r t m e n t, ~ A i n ~ S h a m s ~ U n i v e r s i t y, ~ C a i r o, ~ E g y p t ~}$
\end{abstract}

OBJECTIVE Recurrent or residual adenomas are frequently treated with Gamma Knife radiosurgery (GKRS). The most common complication after GKRS for pituitary adenomas is hypopituitarism. In the current study, the authors detail the timing and types of hypopituitarism in a multicenter, international cohort of pituitary adenoma patients treated with GKRS.

METHODS Seventeen institutions pooled clinical data obtained from pituitary adenoma patients who were treated with GKRS from 1988 to 2016. Patients who had undergone prior radiotherapy were excluded. A total of 1023 patients met the study inclusion criteria. The treated lesions included 410 nonfunctioning pituitary adenomas (NFPAs), 262 cases of Cushing's disease (CD), and 251 cases of acromegaly. The median follow-up was 51 months (range 6-246 months). Statistical analysis was performed using a Cox proportional hazards model to evaluate factors associated with the development of new-onset hypopituitarism.

RESULTS At last follow-up, 248 patients had developed new pituitary hormone deficiency ( 86 with NFPA, 66 with CD, and 96 with acromegaly). Among these patients, $150(60.5 \%)$ had single and $98(39.5 \%)$ had multiple hormone deficiencies. New hormonal changes included 82 cortisol (21.6\%), 135 thyrotropin (35.6\%), 92 gonadotropin (24.3\%), 59 growth hormone (15.6\%), and 11 vasopressin (2.9\%) deficiencies. The actuarial 1-year, 3-year, 5-year, 7-year, and 10-year rates

ABBREVIATIONS $\mathrm{ACTH}=$ adrenocorticotropic hormone; $\mathrm{CD}=$ Cushing's disease; $\mathrm{DI}=$ diabetes insipidus; $\mathrm{FPA}=$ functioning pituitary adenoma; $\mathrm{FSH}=$ follicle-stimulating hormone; GH = growth hormone; GKRS = Gamma Knife radiosurgery; IGF-1 = insulin-like growth factor-1; IGKRF = International Gamma Knife Research Foundation; $\mathrm{NFPA}=$ nonfunctioning pituitary adenoma; $\mathrm{QOL}=$ quality of life; RT = radiation therapy; SRS = stereotactic radiosurgery; $\mathrm{TSH}$ = thyroid-stimulating hormone; $\mathrm{T} 4$ = free thyroxin.

SUBMITTED February 20, 2018. ACCEPTED May 16, 2018.

INCLUDE WHEN CITING Published online November 9, 2018; DOI: 10.3171/2018.5.JNS18509. 
of hypopituitarism were $7.8 \%, 16.2 \%, 22.4 \%, 27.5 \%$, and $31.3 \%$, respectively. The median time to hypopituitarism onset was 39 months.

In univariate analyses, an increased rate of new-onset hypopituitarism was significantly associated with a lower isodose line $(p=0.006, H R=8.695)$, whole sellar targeting $(p=0.033, H R=1.452)$, and treatment of a functional pituitary adenoma as compared with an NFPA ( $p=0.008, H R=1.510)$. In multivariate analyses, only a lower isodose line was found to be an independent predictor of new-onset hypopituitarism ( $p=0.001, \mathrm{HR}=1.38$ ).

CONCLUSIONS Hypopituitarism remains the most common unintended effect of GKRS for a pituitary adenoma. Treating the target volume at an isodose line of $50 \%$ or greater and avoiding whole-sellar radiosurgery, unless necessary, will likely mitigate the risk of post-GKRS hypopituitarism. Follow-up of these patients is required to detect and treat latent endocrinopathies.

https://thejns.org/doi/abs/10.3171/2018.5.JNS18509

KEYWORDS hypopituitarism; pituitary adenoma; Cushing's disease; acromegaly; stereotactic radiosurgery

$\mathrm{P}$ ITUITARY adenomas are among the most common intracranial primary tumors, representing as much as $10 \%-20 \%$ of all of brain tumors. ${ }^{3,78}$ These mostly benign lesions can be classified as either nonfunctioning pituitary adenomas (NFPAs) or functioning pituitary adenomas (FPAs ${ }^{22,23}$ based on clinically and biochemically evident endocrine secretory activity.

With the exception of prolactinomas, most patients with symptomatic NFPAs and FPAs initially undergo resection. After resection, recurrence or progression of a known residual lesion can occur in as many as $10 \%-50 \%$ of pituitary adenomas. ${ }^{6}$ In FPA patients, such recurrence/ progression can lead to a persistent hypersecretory state and related systemic morbidity. Historically, fractionated radiation therapy (RT) was used to treat patients with recurrent or progressive adenomas. However, over the past 2-3 decades, stereotactic radiosurgery (SRS), predominantly with the Gamma Knife, has been increasingly employed in the management of such patients. 2,14,19,28,39

Following SRS, delayed onset of hypopituitarism (any axis) occurs in $20 \%-100 \%$ of patients. $5,21,37$ Other SRS-related adverse effects, such as radiation-induced optic neuropathy and other cranial deficits, have been described. Radiological control of tumor growth has been reported to exceed $90 \%$ in most series of patients treated at high-volume centers, while the endocrine remission (a normal hormone level without medical management) is achieved in 50\%-60\% of patients with Cushing's disease (CD) and acromegaly. ${ }^{12}$ To date, published studies of SRSinduced hypopituitarism have largely been single-center series with a relatively low statistical power and limited follow-up..$^{10,13,27,31,40}$ In the current study, we seek to better define the timing and nature of hypopituitarism after Gamma Knife radiosurgery (GKRS) and identify prognostic factors for its occurrence in a large multicenter cohort through the International Gamma Knife Research Foundation (IGKRF).

\section{Methods \\ Study Coordination}

As part of a multicenter international effort, 17 centers from the IGKRF identified pituitary adenoma patients treated with GKRS between 1988 and 2016. Inclusion criteria included a diagnosis of NFPA, FPA (CD or acro- megaly), and at least one imaging study and a minimum 6-month clinical follow-up. Patients who had undergone previous RT were excluded. Data were pooled by the IGKRF study coordinator, checked for errors, and then sent to the study coordinating site principal investigator at the University of Virginia. The study was approved by institutional review boards at the individual participating centers.

\section{Patients' Attributes}

A total of 1023 patients constituted this multicenter retrospective cohort. Patients were from the 17 centers: University of California 47, Beaumont Health System 6, Ain Shams University and Gamma Knife Center Cairo 16, Benha University 4, Cleveland Clinic 28, Ruber International Hospital 44, NYU Langone Medical Center 14, University of Pennsylvania 16, Na Homolce Hospital 117, Charles University and General University Hospital 4, Université de Sherbrooke 13, Taipei Veterans General Hospital 98, University of Pittsburgh 183, University of Virginia 392, West Virginia University 3, and Yale University 38 .

Table 1 details the patient demographics and characteristics. Overall 642 (62.8\%) had one surgery (craniotomy and resection or transsphenoidal adenomectomy), $296(28.9 \%)$ had multiple resections, 72 patients $(7 \%)$ had upfront GKRS, and 13 patients (1.3\%) had indeterminate treatment.

\section{Endocrine Baseline Information}

The diagnosis of pituitary adenoma was based on clinical, radiological, and endocrine findings. Patients who had undergone a previous surgery had their pathological diagnosis established at each center. Prior to GKRS, patients also underwent a comprehensive endocrine evaluation that included 24-hour urinary free cortisol, adrenocorticotropic hormone (ACTH), serum cortisol, follicle-stimulating hormone (FSH), insulin-like growth factor-1 (IGF-1), growth hormone $(\mathrm{GH})$, testosterone, estradiol, prolactin, thyroid-stimulating hormone (TSH), free thyroxin (T4), and clinical evaluation for diabetes insipidus (DI).

Because the multicenter nature of this cohort mandated gathering patient information from different centers, we therefore relied on clinical evaluations and hormone assessments that were conducted at the individual institution 
TABLE 1. Patient demographics and characteristics

\begin{tabular}{|c|c|c|c|c|c|c|}
\hline \multirow[b]{2}{*}{ Variable } & \multicolumn{2}{|c|}{ Patients } & \multicolumn{2}{|c|}{$\begin{array}{l}\text { Patients w/ New } \\
\text { Hypopituitarism }\end{array}$} & \multicolumn{2}{|c|}{$\begin{array}{c}\text { Patients w/o New } \\
\text { Hypopituitarism }\end{array}$} \\
\hline & No. & $\%$ & No. & $\%$ & No. & $\%$ \\
\hline Total & 1023 & 100 & 248 & 24.2 & 775 & 75.8 \\
\hline Male & 437 & 42.7 & 116 & 26.5 & 454 & 73.5 \\
\hline Female & 586 & 57.3 & 132 & 22.5 & 454 & 77.5 \\
\hline NFPA & 410 & 40.1 & 86 & 21.0 & 324 & 79.0 \\
\hline$C D$ & 262 & 25.6 & 66 & 25.2 & 196 & 74.8 \\
\hline Acromegaly & 351 & 34.3 & 96 & 27.4 & 255 & 72.6 \\
\hline Prior ops & 938 & 91.7 & 233 & 24.8 & 705 & 75.2 \\
\hline $\begin{array}{l}\text { Suprasellar } \\
\text { extension }\end{array}$ & 200 & 19.6 & 49 & 24.5 & 151 & 75.5 \\
\hline CS invasion & 584 & 57.1 & 142 & 24.3 & 442 & 75.7 \\
\hline Whole-sellar Tx & 153 & 15.0 & 49 & 32.0 & 104 & 68.0 \\
\hline
\end{tabular}

CS = cavernous sinus; $\mathrm{Tx}=$ treatment.

and laboratories and/or provided by primary care physicians in different healthcare facilities.

\section{GKRS Technique}

The GKRS technique for the treatment of patients with pituitary adenomas has been described in detail. ${ }^{33}$ In brief, a stereotactic Leksell stereotactic Gamma Knife frame was placed after the patient had received local anesthesia coupled with monitored sedation as needed. To better elucidate the pituitary adenoma, we used an MRI protocol of thin slices $(1 \mathrm{~mm})$ before and after contrast administration, often combined with fat suppression. This multicenter, international study involved different institutions with clinical data spanning a few decades. As such, a variety of Gamma Knife models were used, including model U, model C, Perfexion, and Icon, depending on the time of treatment and the treatment site. The recurrence or progression of a pituitary adenoma, postoperative residual (more frequent with cavernous sinus invasion), and hypersecretory state (FPA) were common indications for GKRS.

The GKRS dose plan was determined by a team made up of a neurosurgeon, radiation oncologist, and medical physicist, and depended on tumor type, tumor volume, prior cranial nerve deficits, and proximity of the lesion to the brainstem and optic apparatus. At many centers, patients with FPAs were encouraged to discontinue any antisecretory medication prior to GKRS, a clinical protocol that started around year 2001. Dopamine agonists were discontinued 4 weeks before GKRS and cortisol-lowering drugs and somatostatin analogs were discontinued 6-8 weeks before GKRS. ${ }^{28,29,33}$ The median margin dose to FPAs was $25 \pm 6.5$ Gy (range 3.0-40.0 Gy), and the median margin dose to NFPAs was $16.0 \pm 4.23$ Gy (range 5-35 Gy). The median follow-up duration was 51 months (range 6-246 months). Table 2 summarizes the patient characteristics and GKRS parameters.

\section{Follow-Up Protocol}

Follow-up schedules differed to some extent among the different centers. A general scheme involved a scheduled follow-up visit every 6 months after GKRS during the 1st year or two and then annually thereafter. Neurosurgical, endocrine, and radiological encounters were generally scheduled at the same time. Patients had clinical evaluation performed by both neurosurgeons and endocrinologists, underwent dedicated MRI brain scanning, and had hormone studies performed as routine at regular visits.

Endocrine follow-up visits included periodic laboratory tests for serum cortisol, ACTH, FSH, IGF-1, GH, testosterone, estradiol, prolactin, TSH, T4, and clinical assessment for DI. New-onset post-GKRS hypopituitarism was defined as a pituitary hormone deficiency (of those listed above) that required hormone replacement at any time after GKRS. Hypopituitarism that developed prior to the time of GKRS was found in 383 patients (37.4\%). In detail, a corticotroph deficiency was defined as any value below the normal range in the investigations of serum cortisol. A thyrotroph deficiency was diagnosed based on a low T4 with a normal or decreased TSH hormone level; a gonadotroph deficiency was defined as low or normal gonadotropin levels and low plasma testosterone in men and amenorrhea with low plasma estradiol in premenopausal women; and a GH deficiency was defined as a low IGF1 or a subnormal GH response during a stimulation test adjusted by the patient age and sex.

Tumor control was defined as no growth (tumor volume with a change within $\pm 10 \%$ of the pretreatment volume)

TABLE 2. Summary of patients and GKRS characteristics

\begin{tabular}{|c|c|c|c|c|c|c|}
\hline \multirow[b]{2}{*}{ Variable } & \multicolumn{2}{|c|}{ Entire Study } & \multicolumn{2}{|c|}{ Patients w/ New Hypopituitarism } & \multicolumn{2}{|c|}{ Patients w/o New Hypopituitarism } \\
\hline & Median & Range & Median & Range & Median & Range \\
\hline Age at SRS, yrs & 47 & $12-92$ & 44.51 & $14-88$ & 48 & $12-92$ \\
\hline Prior op, no. & 1 & $0-7$ & 1 & $0-3$ & 1 & $0-7$ \\
\hline Treated vol, $\mathrm{cm}^{3}$ & 2.47 & $0.1-58.1$ & 2.8 & $0.1-37.3$ & 2.3 & $0.1-58.1$ \\
\hline Margin dose, Gy & 20 & $3-40$ & 20 & $3-40$ & 20 & $5-40$ \\
\hline Max dose, Gy & 40 & $10-83.30$ & 41.29 & $10-80$ & 40 & $10-83.3$ \\
\hline Isocenters & 7 & $1-40$ & 8.54 & $1-23$ & 7 & $1-40$ \\
\hline IDL, \% & 50 & $20-90$ & 50 & $20-90$ & 50 & $20-90$ \\
\hline
\end{tabular}




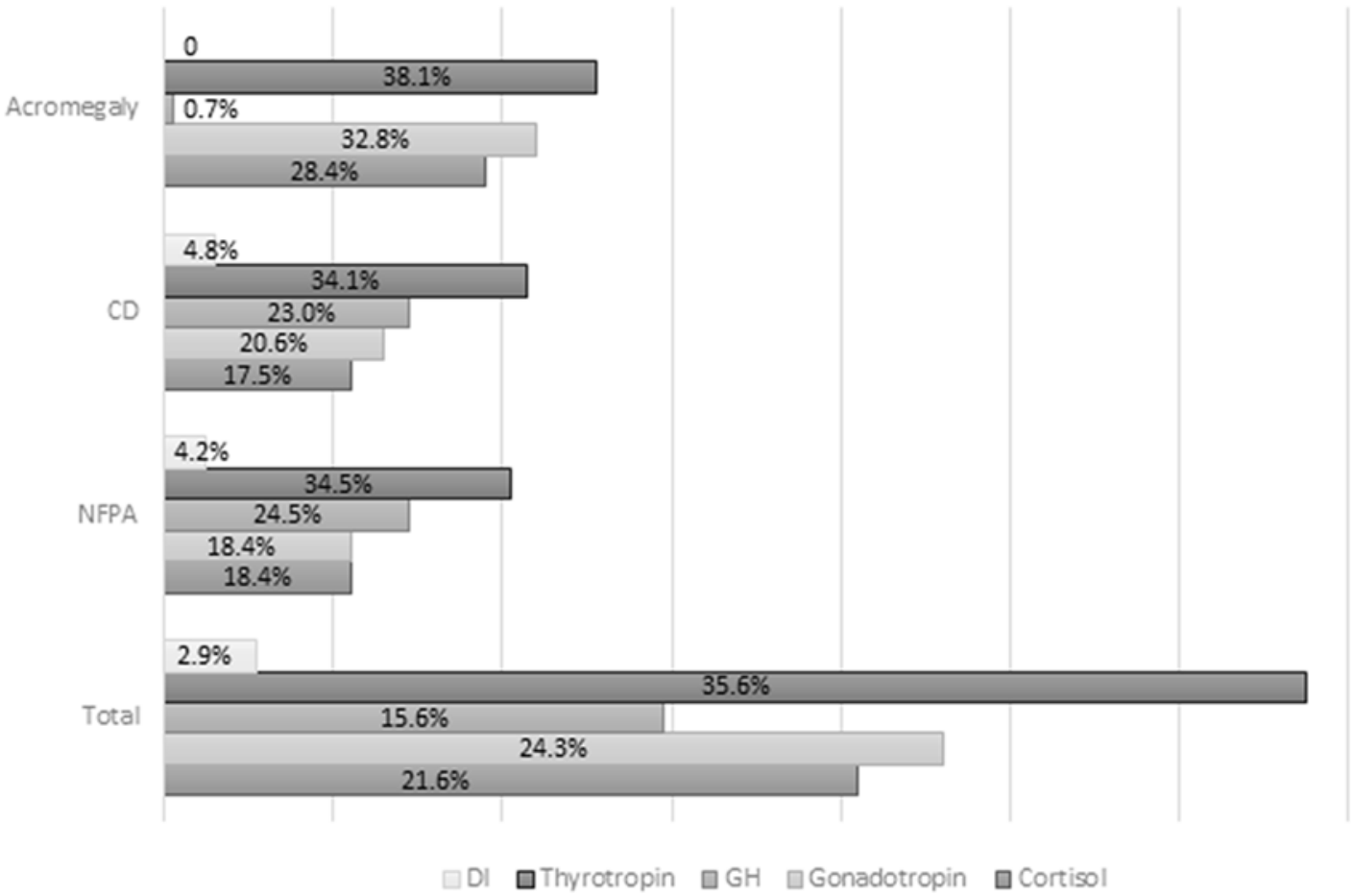

FIG. 1. New hormone deficiencies in patients with different types of adenoma.

or shrinkage ( $>10 \%)$ of pituitary adenomas, and radiological failure was considered tumor growth of $>10 \%$ of the pretreatment volume demonstrated on MRI brain scans at routine follow-up visits. ${ }^{35}$

\section{Statistical Analysis}

Statistical analysis was performed using a Cox proportional hazards regression model to evaluate prognostic factors associated with the time to new-onset hypopituitarism following GKRS. The assumption of proportional hazard was confirmed using a log-minus-log method prior to the analysis. Variables with a p value $\leq 0.1$ in all univariate analyses were subsequently enrolled in a multivariate analysis. The one-way ANOVA was used to determine whether there were any statistically significant differences between the means of more than two unrelated groups in relation to tumor type, isodose line, and status of wholesellar treatment. Kaplan-Meier plots were employed to assess the new onset of hypopituitarism. Logistic regression was used to evaluate radiological tumor control. All statistical analyses were conducted using a commercially available statistical package (IBM SPSS version 24.0). All the statistical studies were two-sided and a $\mathrm{p}$ value $<0.05$ was deemed statistically significant.

\section{Results}

\section{Time of New-Onset Hypopituitarism Following SRS}

At last follow-up, 248 patients $(24.2 \%)$ had developed new hypopituitarism. Among them, 150 patients had a single hormonal deficiency and 98 had multiple hormone deficiencies; only 7 patients developed panhypopituita- rism. Hypopituitarism occurred in 86 NFPA (34.68\%), 66 CD (26.61\%), and 96 acromegalic $(38.71 \%)$ patients. The actuarial hypopituitarism rates at $1,3,5,7$, and 10 years were $7.8 \%, 16.2 \%, 22.4 \%, 27.5 \%$, and $31.3 \%$, respectively. The median time to onset of new hypopituitarism was 39 months (range 3-171.60 months). New hormonal changes included 82 cortisol (21.6\%), 135 thyrotropin (35.6\%), 92 gonadotropin (24.3\%), 59 growth hormone (15.6\%), and 11 vasopressin $(2.9 \%)$ deficiencies. Figure 1 indicates new endocrine deficiencies by adenoma type.

In the univariate analysis, an increased rate of newonset hypopituitarism was significantly associated with the following factors: lower isodose line prescribed $(\mathrm{p}=$ $0.006, \mathrm{HR}=8.695)$, whole-sellar targeting $(\mathrm{p}=0.033$, HR $=1.452)$, and an FPA as opposed to an NFPA ( $p=0.008$, $\mathrm{HR}=1.510$ ). In multivariate analyses, treatment with a lower isodose line was associated with an increased rate of new-onset hypopituitarism ( $\mathrm{p}=0.001, \mathrm{HR}=1.38$ ). For every $10 \%$ reduction of the isodose line treatment, there was an accompanying increased risk rate of $27 \%$ of new hypopituitarism after GKRS. Previous surgery, hypopituitarism before GKRS, margin and maximum dose, cavernous sinus invasion, suprasellar extension, and treated volume were factors not associated with post-GKRS hypopituitarism. Extended follow-up did not show any appreciably increased risk. Table 3 summarizes the statistical analyses.

Patient demographics, tumor characteristics, planning treatment, time to new-onset hypopituitarism, and radiological control stratified by isodose line are displayed in Table 4 . The most statistically significant variable was the decreasing treatment isodose line, which was associated 
TABLE 3. Univariate and multivariate analyses of potential prognostic factors contributing to the time of new-onset hypopituitarism after SRS

\begin{tabular}{|c|c|c|c|c|c|c|c|c|}
\hline \multirow[b]{3}{*}{ Variable } & \multicolumn{4}{|c|}{ Univariate Analysis } & \multicolumn{4}{|c|}{ Multivariate Analysis } \\
\hline & \multirow[b]{2}{*}{$p$ Value } & \multirow[b]{2}{*}{$H R$} & \multicolumn{2}{|c|}{$95 \% \mathrm{Cl}$} & \multirow[b]{2}{*}{ p Value } & \multirow[b]{2}{*}{$\mathrm{HR}$} & \multicolumn{2}{|c|}{$95 \% \mathrm{Cl}$} \\
\hline & & & Lower & Upper & & & Lower & Upper \\
\hline Age at SRS & 0.053 & 0.991 & 0.982 & 1.00 & 0.082 & 0.99 & 0.979 & 1.001 \\
\hline CS invasion & 0.983 & 0.997 & 0.759 & 1.309 & & & & \\
\hline Suprasellar extension & 0.879 & 1.028 & 0.722 & 1.462 & & & & \\
\hline Whole-sellar Tx & 0.033 & 1.452 & 1.031 & 2.047 & 0.117 & 1.321 & 0.933 & 1.87 \\
\hline Margin dose & 0.816 & 0.998 & 0.979 & 1.017 & & & & \\
\hline Max dose & 0.331 & 1.005 & 0.995 & 1.014 & & & & \\
\hline Hypopituitarism at time of GKRS & 0.189 & 0.822 & 0.614 & 1.101 & & & & \\
\hline Tx vol & 0.829 & 1.003 & 0.973 & 1.035 & & & & \\
\hline IDL & 0.006 & 8.695 & 1.872 & 40.00 & 0.001 & 1.38 & 1.14 & 1.67 \\
\hline FPA vs NFPA & 0.008 & 1.51 & 1.113 & 2.048 & 0.871 & 1.07 & 0.471 & 2.434 \\
\hline Previous op & 0.085 & 1.669 & 0.932 & 2.99 & & & & \\
\hline No. of previous ops & 0.736 & 1.035 & 0.848 & 1.263 & & & & \\
\hline
\end{tabular}

Analyses performed using Cox regression models.

with an increasing rate of risk of new-onset endocrine deficiencies.

The majority of the patients $(\mathrm{n}=771)$ were treated with a $50 \%$ isodose line; of these, $342(44.4 \%)$ had NFPAs, 186 (24.1\%) had CD, and 243 (31.5\%) had acromegaly. One hundred forty-eight patients were treated with an isodose line greater than 50\%; of these, 6 patients (4.1\%) had NFPAs, 54 (36.5\%) had CD, and $88(59.5 \%)$ had acromegaly. One hundred three patients were treated with an isodose line less than 50\%; of these, $62(60.1 \%)$ had NFPAs, 22 (21.4\%) had CD, and 20 (19.4\%) had acromegaly. The Kaplan-Meier plot (Fig. 2) shows how patients with FPAs in relation to NFPAs are more prone to developing new-onset hypopituitarism after GKRS, and the other Kaplan-Meier plot (Fig. 3) illustrates the increased risk of lower isodose line treatments on the onset of new hypopituitarism.

\section{Radiological Response}

The median imaging follow-up period was 51 months (range 6-246 months). At last follow-up, tumor control was achieved in 985 patients (96.3\%), and 38 patients (3.7\%) had adenoma progression after GKRS. Of those with adenoma progression, 23 had NFPAs, 11 had CD, and 4 had acromegaly. In the logistic regression analysis, improved tumor control rates were related to an increasing margin dose and maximum dose, FPA versus NFPA, no suprasellar extension, and reduced treatment volume (Table 5). We did not find any statistical correlation between tumor control and hypopituitarism after GKRS in logistic regression analysis ( $\mathrm{p}=0.636$; $\mathrm{OR}=1.004,95 \%$ CI 0.986-1.023).

\section{Discussion}

The first scientific study to investigate the overall prevalence and incidence of hypopituitarism in a population was done in Spain with a sample size of 146,000 people.
The first survey found the overall prevalence of hypopituitarism to be 29 per 100,000 , and the second survey found it to be closer to 45.5 per $100,000 .{ }^{30}$ Hypopituitarism is defined as a biochemical deficiency associated with one or more hormonal axes of the anterior and/or posterior pituitary gland. It can occur as a result of dysfunction of the pituitary gland or as a result of hypothalamic damage. Hypopituitarism can be primary due to pituitary dysfunction or secondary to other disease such as pituitary adenomas. These tumors can cause hypopituitarism because of adenoma growth and resulting compression on the normal pituitary gland and stalk. It can also arise as a result of iatrogenic injury to the normal neuroendocrine structures during treatments such as surgery, radiosurgery, and RT. . $^{5,18}$

If undetected and uncorrected, hypopituitarism can have appreciable morbidity and even mortality. A recent meta-analysis demonstrated that hypopituitarism is associated with an overall excess mortality. This could be explained by metabolic changes associated with hormonal imbalance, radiation-induced vasculopathy or atherosclerosis related to pituitary insufficiency, and prothrombotic states. Some studies of hypopituitary patients have shown that younger age and female sex are risk factors for a high mortality rate..$^{15,20}$

Patients who develop hypopituitarism also have a poor quality of life (QOL). This impact on QOL tends to be more severe in patients with $\mathrm{CD}$ and acromegaly than in those with NFPA and prolactinomas. The presence of multiple pituitary deficiencies further worsens QOL. Despite optimal endocrine replacement, QOL often remains below reference values. These QOL studies on hypopituitarism reveal the importance of long-term follow-up of these patients, proper diagnosis, and adequate hormonal replacement when necessary. ${ }^{16,38}$

In the current study, we found that $24.2 \%$ of patients developed new-onset hypopituitarism following GKRS, and this is comparable to rates published in several prior 
TABLE 4. Patient demographics, tumor characteristics, planning treatment, time to new-onset hypopituitarism, and tumor control by isodose line

\begin{tabular}{|c|c|c|c|}
\hline Frequencies by IDL & IDL <50 Gy & IDL 50 Gy & IDL >50 Gy \\
\hline No. of patients & 103 & 771 & 148 \\
\hline Median age, yrs & 49 & 47 & 45.31 \\
\hline Prior op, no. & $97(94.2 \%)$ & $712(92.3 \%)$ & $128(86.5 \%)$ \\
\hline $\begin{array}{l}\text { Median treated vol, } \\
\mathrm{cm}^{3}\end{array}$ & 3.564 & 3.597 & 3.602 \\
\hline CS invasion, no. & $60(58.3 \%)$ & $469(60.8 \%)$ & $54(36.5 \%)$ \\
\hline $\begin{array}{l}\text { Suprasellar exten- } \\
\text { sion, no. }\end{array}$ & $22(21.4 \%)$ & $166(21.5 \%)$ & $11(7.4 \%)$ \\
\hline Whole-sellar Tx, no. & $8(7.8 \%)$ & $135(17.5 \%)$ & $10(7.0 \%)$ \\
\hline $\begin{array}{l}\text { Median margin } \\
\text { dose, Gy }\end{array}$ & 15.00 & 20.00 & 20.00 \\
\hline $\begin{array}{l}\text { Median max dose, } \\
\text { Gy }\end{array}$ & 50.00 & 40.10 & 30.84 \\
\hline $\begin{array}{l}\text { Median no. of } \\
\text { isocenters }\end{array}$ & 5.00 & 8.00 & 8.00 \\
\hline $\begin{array}{l}\text { New-onset hypopi- } \\
\text { tuitarism, no. }\end{array}$ & $30(29.1 \%)$ & $190(24.6 \%)$ & $28(18.9 \%)$ \\
\hline $\begin{array}{l}\text { Median time to new } \\
\text { hypopituitarism } \\
\text { (range), mos }\end{array}$ & $13(4.70-171.60)$ & $18(3-143.9)$ & $46.50(13-153)$ \\
\hline $\begin{array}{l}\text { Mean time to new } \\
\text { hypopituitarism, } \\
\text { mos }\end{array}$ & 25.2285 & 50.68 & 53.73 \\
\hline $\begin{array}{l}\text { Radiological con- } \\
\text { trol, no. }\end{array}$ & $94(91.3 \%)$ & 747 (96.9\%) & $143(96.6 \%)$ \\
\hline
\end{tabular}

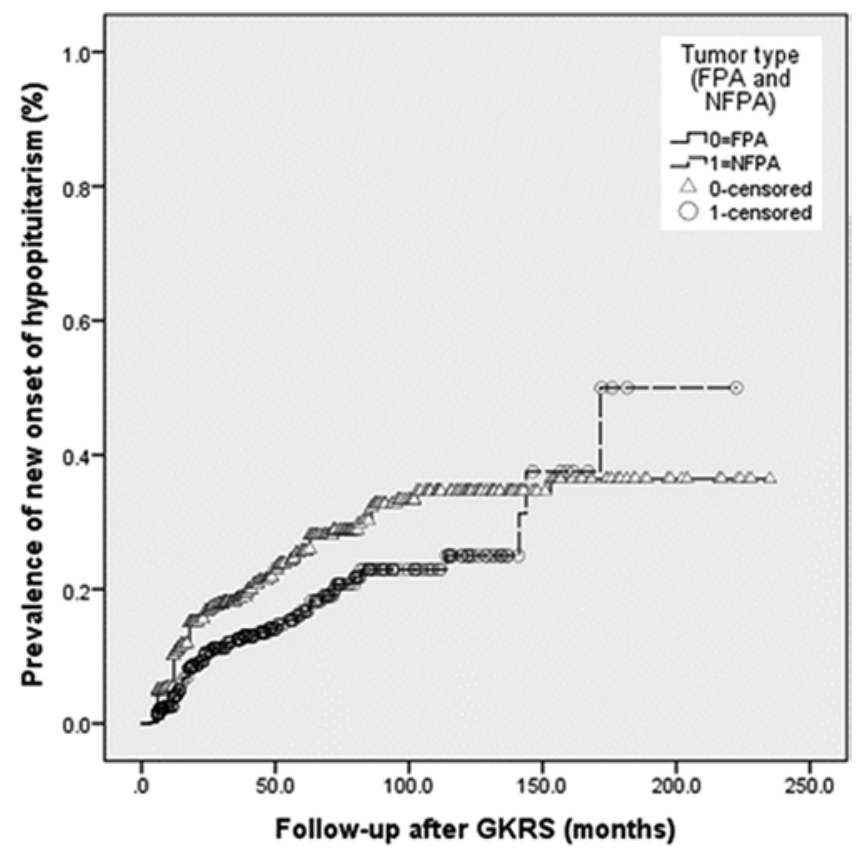

FIG. 2. Kaplan-Meier plot of time to new-onset hypopituitarism related to NFPA and FPA.
SRS reports. ${ }^{32,33}$ This incidence is also lower than the historic risk of hypopituitarism following RT, which is believed to be as high as $50 \% .{ }^{36}$ The timing for new-onset hypopituitarism is typically within 5 years after SRS, whereas post-RT hypopituitarism typically occurs even before $1-10$ years after treatment. ${ }^{21}$

The prescription of an increasing isodose line portended a lower risk of new-onset hypopituitarism after adjusting for other parameters, including age at GKRS, margin dose, and adenoma type. The use of a much lower isodose line at the margin can lead to a dramatic increase in the maximum dose delivered to the target, although this would also increase the total energy delivered to normal surrounding structures ${ }^{34}$ such as the normal pituitary gland, pituitary stalk, and hypothalamus.

Lower isodose plans likely conveyed a poor gradient index, and they are a surrogate for an increased radiosurgical dose delivered to critical structures, as can be seen in Table 4; despite a lower median margin dose (15 Gy), isodose lines less than $50 \%$ had a maximum dose of 50 Gy, compared with a prescribed isodose line of $50 \%$ or more than $50 \%$ that had median maximum doses of 40.1 Gy and 30.84 Gy, respectively. The established rationale for prescribing a $50 \%$ or higher isodose line in GKRS is that the dose distribution maximizes the gradient just beyond the tumor edge and thus minimizes the dose to adjacent organs at risk. Achieving conformal coverage of the target with a higher isodose line would enable the tumor to receive more homogeneous high-dose radiation with an increased mean dose. Since the adenoma is receiving an increased mean dose, the treatment dose can be optimized by reducing the maximum dose delivered to the center of the target while maintaining the same dose

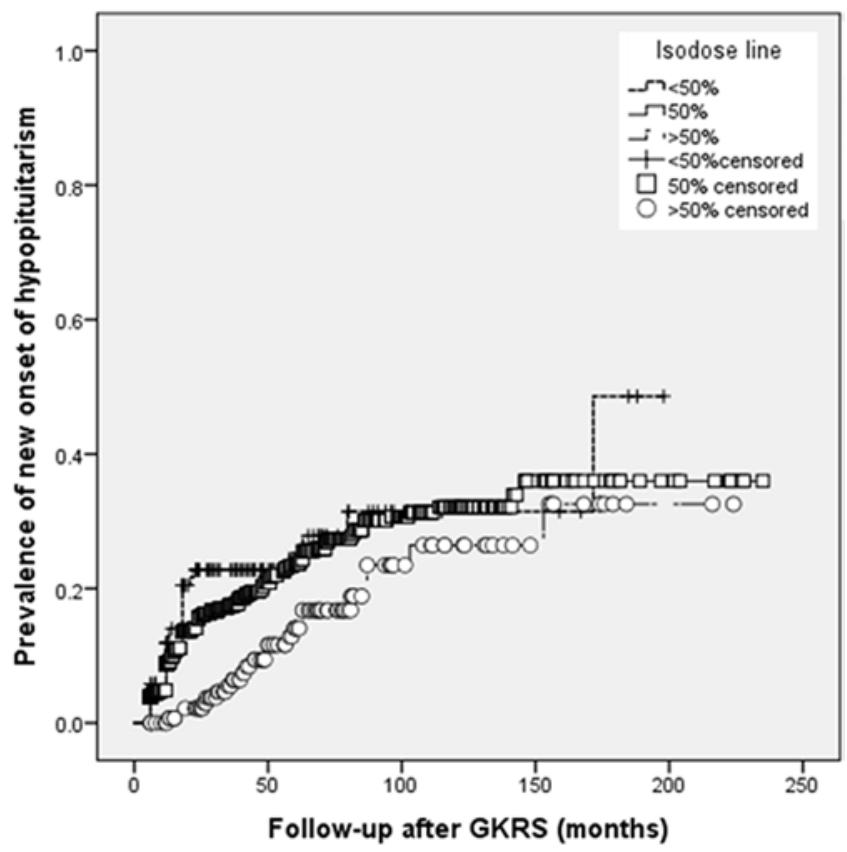

FIG. 3. Kaplan-Meier plot of time to new-onset hypopituitarism in relation to the isodose line prescription. 
TABLE 5. Factors related to tumor control

\begin{tabular}{lrccc}
\hline & \multicolumn{4}{c}{ Logistic Regression } \\
\cline { 2 - 5 } \multicolumn{1}{c}{ Factor } & & & \multicolumn{2}{c}{$95 \% \mathrm{Cl}$} \\
\cline { 4 - 5 } & $\mathrm{p}$ Value & OR & Lower & Upper \\
\hline Age at GKRS & 0.766 & 0.997 & 0.975 & 1.019 \\
\hline CS invasion & 0.806 & 0.922 & 0.48 & 1.768 \\
\hline Suprasellar extension & 0.002 & 2.912 & 1.482 & 5.721 \\
\hline Whole-sellar Tx & 0.401 & 1.595 & 0.537 & 4.739 \\
\hline Margin dose & $<0.001$ & 0.877 & 0.821 & 0.936 \\
\hline Max dose & $<0.001$ & 0.946 & 0.917 & 0.976 \\
\hline New hypopituitarism & 0.636 & 1.004 & 0.986 & 1.023 \\
\hline Treated vol & 0.011 & 1.062 & 1.014 & 1.112 \\
\hline IDL & 0.095 & 0.043 & 0.001 & 1.727 \\
\hline FPA vs NFPA & 0.011 & 2.369 & 1.221 & 4.598 \\
\hline Isocenters & 0.716 & 1.011 & 0.953 & 1.073 \\
\hline Previous op & 0.493 & 1.656 & 0.392 & 7.001 \\
\hline
\end{tabular}

in the margin, and the surrounding normal tissues can receive less radiation, thereby possibly reducing the risk of hypopituitarism.

\section{Comparing Hypopituitarism From Resection, RT, and SRS}

The incidence of hypopituitarism following surgery varies from $10 \%$ to $25 \%$., 26 Post-resection hypopituitarism has been reported to be associated with larger adenoma size, the degree to which the adenoma invades the cavernous sinus, the quantity of normal gland remaining after resection, and the experience of the treating neurosurgeon. ${ }^{1,25}$ Endocrinopathies of the anterior pituitary gland are the most common complication after resection and have an incidence of 2\%-22\%. DI following resection occurs in $0.4 \%-15 \%$ of cases but is typically transient $(3 \%)$ or less permanent. ${ }^{9,25,26}$

RT has also been associated with hypopituitarism in $50 \%-100 \%$ of cases. The typical timing of hypopituitarism onset after RT is as soon as 6-12 months, with a range of 1-10 years. ${ }^{4,36}$ Endocrine axes affected after RT are most common, in a decreasing order of frequency: GH, gonadotropins, ACTH, and TSH. Hyperprolactinemia can also occur due to hypothalamic damage leading to reduced dopamine release. Hyperprolactinemia has been described in both sexes and in individuals of all ages but is mostly seen in young women after intensive irradiation and is usually subclinical. Factors that portend a greater risk of post-RT hypopituitarism are higher-dose treatments and the time elapsed since irradiation. ${ }^{4,36}$

In a study by Feigl et al., ${ }^{11}$ GKRS seemed a safe and effective treatment for patients with residual and recurrent pituitary adenomas. The rate of pituitary insufficiency after GKRS is lower than that after conventional RT. The results of the present study show that patients in whom the pituitary stalk and pituitary gland receive a higher mean point dose are more likely to develop pituitary insufficiencies after GKRS than those who receive a lower dose and, furthermore, that the dose delivered to the hypothalamus is usually very low. However, long-term follow-up studies of GKRS-treated pituitary tumors are scarce. Previous studies have reported rates of new hormone deficiency ranging between $0 \%$ and $40 \% .{ }^{24}$ Gopalan et al. ${ }^{12}$ found a $39 \%$ rate of new hormone deficiency, with the most common new hormone deficits being thyroid hormone and $\mathrm{GH}$; the actuarial rate of endocrinopathy in their study increased from $12.5 \%$ at 24 months to $50.7 \%$ at 120 months, with an estimated mean time to loss of pituitary function of 112 months. In a recent study, $\mathrm{Xu}$ et $\mathrm{al} .{ }^{41}$ reported hypopituitarism in $30 \%$ of patients following GKRS; they found that a higher margin dose and suprasellar extension of a pituitary adenoma were risk factors associated with new onset of endocrine deficiencies.

An increased risk of hypopituitarism has been shown to be associated with the radiosurgical targeting of the whole sella in selected patients with CD in whom no discrete adenoma was identified on MRI. ${ }^{17}$ The current study validates prior findings. Intuitively, patients in whom the remaining normal gland received the prescription dose should be carefully followed for post-SRS hypopituitarism. Unlike following resection, post-SRS posterior pituitary insufficiency occurred in only $4.6 \%$ of patients. Anterior pituitary deficiency in our study occurred more commonly than posterior pituitary deficiency, and the ratio of anterior pituitary deficits to posterior pituitary deficits was 20 to 1 .

We found that only $15.3 \%$ of all the patients with newonset hypopituitarism developed new endocrine deficits in a time frame of more than 5 years after SRS. While infrequent, very delayed-onset hypopituitarism after GKRS can occur, and this does underscore the importance of longitudinal endocrine follow-up of these patients to detect deficiencies and treat them with appropriate replacement therapy to minimize the impact in the QOL and reduce the risk of mortality.

\section{Study Limitations}

While this study is composed of multicenter data and represents the largest such study to date, it does have limitations. The study has the limitations inherent in a retrospective design, including selection bias and treatment, as well as follow-up variations. Participating centers represent tertiary referral centers that draw patients from afar. While every attempt was made to have the patients undergo follow-up with their treating physicians, some patients chose to have follow-up with their local physicians, and the information gathered in such cases was therefore based on endocrine testing by local clinicians. While all patients were treated with a common radiosurgical platform, the treatments spanned several decades, during which the Gamma Knife technology, neuroimaging protocols, and radiosurgical techniques evolved. Also, post-GKRS endocrine testing was performed at the discretion of the treating team, and the timing of the testing was not always uniform; irregularities in endocrine testing time could have impacted the time to new-onset hypopituitarism. Moreover, endocrine testing assays and normal ranges have changed over the study period. Thus, the current study may underestimate the degree of hypopituitarism. While there are limitations to the current study, the delayed effect 
of hypopituitarism after GKRS makes a prospective study of this topic logistically challenging.

\section{Conclusions}

Hypopituitarism remains the most common adverse effect of GKRS for pituitary adenoma patients. Treating the target volume at an isodose line of $50 \%$ or greater and avoiding whole-sellar radiosurgery unless necessary will likely mitigate the risk of post-GKRS hypopituitarism. While the majority of hypopituitarism occurs within the first $1-5$ years after GKRS, delayed hypopituitarism, even beyond 10 years, can occur, and therefore, longitudinal follow-up of these patients is required to detect and replace any endocrine deficiencies when appropriate.

\section{References}

1. Ahmed S, Elsheikh M, Stratton IM, Page RC, Adams CB, Wass JA: Outcome of transphenoidal surgery for acromegaly and its relationship to surgical experience. Clin Endocrinol (Oxf) 50:561-567, 1999

2. Castinetti F, Régis J, Dufour H, Brue T: Role of stereotactic radiosurgery in the management of pituitary adenomas. Nat Rev Endocrinol 6:214-223, 2010

3. Cushing H: The Pituitary Body and its Disorders. Clinical States Produced by Disorders of the Hypophysis Cerebri. Philadelphia: J.B. Lippincott, 1912

4. Darzy KH: Radiation-induced hypopituitarism after cancer therapy: who, how and when to test. Nat Clin Pract Endocrinol Metab 5:88-99, 2009

5. Darzy KH, Shalet SM: Hypopituitarism following radiotherapy revisited. Endocr Dev 15:1-24, 2009

6. Dekkers OM, Pereira AM, Roelfsema F, Voormolen JH, Neelis KJ, Schroijen MA, et al: Observation alone after transsphenoidal surgery for nonfunctioning pituitary macroadenoma. J Clin Endocrinol Metab 91:1796-1801, 2006

7. Dekkers OM, Pereira AM, Romijn JA: Treatment and followup of clinically nonfunctioning pituitary macroadenomas. J Clin Endocrinol Metab 93:3717-3726, 2008

8. Ezzat S, Asa SL, Couldwell WT, Barr CE, Dodge WE, Vance ML, et al: The prevalence of pituitary adenomas: a systematic review. Cancer 101:613-619, 2004

9. Fatemi N, Dusick JR, Mattozo C, McArthur DL, Cohan P, Boscardin J, et al: Pituitary hormonal loss and recovery after transsphenoidal adenoma removal. Neurosurgery 63:709719, 2008

10. Feigl GC, Bonelli CM, Berghold A, Mokry M: Effects of gamma knife radiosurgery of pituitary adenomas on pituitary function. J Neurosurg 97 (5 Suppl):415-421, 2002

11. Feigl GC, Pistracher K, Berghold A, Mokry M: Pituitary insufficiency as a side effect after radiosurgery for pituitary adenomas: the role of the hypothalamus. J Neurosurg $\mathbf{1 1 3}$ Suppl:153-159, 2010

12. Gopalan R, Schlesinger D, Vance ML, Laws E, Sheehan J: Long-term outcomes after Gamma Knife radiosurgery for patients with a nonfunctioning pituitary adenoma. Neurosurgery 69:284-293, 2011

13. Höybye C, Rähn T: Adjuvant Gamma Knife radiosurgery in non-functioning pituitary adenomas; low risk of long-term complications in selected patients. Pituitary 12:211-216, 2009

14. Jane JA Jr, Vance ML, Woodburn CJ, Laws ER Jr: Stereotactic radiosurgery for hypersecreting pituitary tumors: part of a multimodality approach. Neurosurg Focus 14(5):e12, 2003

15. Jasim S, Alahdab F, Ahmed AT, Tamhane S, Prokop LJ, Nippoldt TB, et al: Mortality in adults with hypopituitarism: a systematic review and meta-analysis. Endocrine 56:33-42, 2017

16. Johnson MD, Woodburn CJ, Vance ML: Quality of life in patients with a pituitary adenoma. Pituitary 6:81-87, 2003

17. Lee CC, Chen CJ, Yen CP, Xu Z, Schlesinger D, Fezeu F, et al: Whole-sellar stereotactic radiosurgery for functioning pituitary adenomas. Neurosurgery 75:227-237, 2014

18. Leenstra JL, Tanaka S, Kline RW, Brown PD, Link MJ, Nippoldt TB, et al: Factors associated with endocrine deficits after stereotactic radiosurgery of pituitary adenomas. Neurosurgery 67:27-33, 2010

19. Leksell L: The stereotaxic method and radiosurgery of the brain. Acta Chir Scand 102:316-319, 1951

20. Lindholm J, Nielsen EH, Bjerre P, Christiansen JS, Hagen C, Juul S, et al: Hypopituitarism and mortality in pituitary adenoma. Clin Endocrinol (Oxf) 65:51-58, 2006

21. Littley MD, Shalet SM, Beardwell CG, Ahmed SR, Applegate G, Sutton ML: Hypopituitarism following external radiotherapy for pituitary tumours in adults. Q J Med 70:145160,1989

22. Lloyd RV, Osamura RY, Kloppel G, Rosai J (eds): WHO Classification of Tumours of Endocrine Organs, ed 4. Lyon, France: International Agency for Research on Cancer, 2017

23. Lopes MBS: The 2017 World Health Organization classification of tumors of the pituitary gland: a summary. Acta Neuropathol 134:521-535, 2017

24. Minniti G, Jaffrain-Rea ML, Osti M, Cantore G, Enrici RM: Radiotherapy for nonfunctioning pituitary adenomas: from conventional to modern stereotactic radiation techniques. Neurosurg Rev 30:167-176, 2007

25. Nomikos P, Buchfelder M, Fahlbusch R: The outcome of surgery in 668 patients with acromegaly using current criteria of biochemical 'cure'. Eur J Endocrinol 152:379-387, 2005

26. Nomikos P, Ladar C, Fahlbusch R, Buchfelder M: Impact of primary surgery on pituitary function in patients with nonfunctioning pituitary adenomas - a study on 721 patients. Acta Neurochir (Wien) 146:27-35, 2004

27. Petrovich Z, Yu C, Giannotta SL, Zee CS, Apuzzo ML: Gamma knife radiosurgery for pituitary adenoma: early results. Neurosurgery 53:51-61, 2003

28. Pollock BE, Jacob JT, Brown PD, Nippoldt TB: Radiosurgery of growth hormone-producing pituitary adenomas: factors associated with biochemical remission. J Neurosurg 106:833-838, 2007

29. Pollock BE, Nippoldt TB, Stafford SL, Foote RL, Abboud $\mathrm{CF}$ : Results of stereotactic radiosurgery in patients with hormone-producing pituitary adenomas: factors associated with endocrine normalization. J Neurosurg 97:525-530, 2002

30. Regal M, Páramo C, Sierra SM, Garcia-Mayor RV: Prevalence and incidence of hypopituitarism in an adult Caucasian population in northwestern Spain. Clin Endocrinol (Oxf) 55:735-740, 2001

31. Sheehan JP, Kondziolka D, Flickinger J, Lunsford LD: Radiosurgery for residual or recurrent nonfunctioning pituitary adenoma. J Neurosurg 97 (5 Suppl):408-414, 2002

32. Sheehan JP, Niranjan A, Sheehan JM, Jane JA Jr, Laws ER, Kondziolka D, et al: Stereotactic radiosurgery for pituitary adenomas: an intermediate review of its safety, efficacy, and role in the neurosurgical treatment armamentarium. J Neurosurg 102:678-691, 2005

33. Sheehan JP, Pouratian N, Steiner L, Laws ER, Vance ML: Gamma Knife surgery for pituitary adenomas: factors related to radiological and endocrine outcomes. J Neurosurg 114:303-309, 2011

34. Shiue K, Barnett GH, Suh JH, Vogelbaum MA, Reddy CA, Weil RJ, et al: Using higher isodose lines for gamma knife treatment of 1 to 3 brain metastases is safe and effective. Neurosurgery 74:360-366, 2014

35. Snell JW, Sheehan J, Stroila M, Steiner L: Assessment of im- 
aging studies used with radiosurgery: a volumetric algorithm and an estimation of its error. Technical note. J Neurosurg 104:157-162, 2006

36. Toogood AA: Endocrine consequences of brain irradiation. Growth Horm IGF Res 14 (Suppl A):S118-S124, 2004

37. Vance ML: Hypopituitarism. N Engl J Med 330:1651-1662, 1994

38. Webb SM, Crespo I, Santos A, Resmini E, Aulinas A, Valassi E: Management of endocrine disease: quality of life tools for the management of pituitary disease. Eur J Endocrinol 177:R13-R26, 2017

39. Witt TC: Stereotactic radiosurgery for pituitary tumors. Neurosurg Focus 14(5): e10, 2003

40. Wowra B, Stummer W: Efficacy of gamma knife radiosurgery for nonfunctioning pituitary adenomas: a quantitative follow up with magnetic resonance imaging-based volumetric analysis. J Neurosurg 97 (5 Suppl):429-432, 2002

41. Xu Z, Lee Vance M, Schlesinger D, Sheehan JP: Hypopituitarism after stereotactic radiosurgery for pituitary adenomas. Neurosurgery 72:630-637, 2013

\section{Disclosures}

Dr. Lunsford reports being a consultant for Insightec DSMB and having direct stock ownership in Elekta. Dr. Grills reports having direct stock ownership in Greater Michigan Gamma Knife, where she is on the executive board of directors, and she reports receiving, through her institution, research funding from Elekta that is unrelated to the present study.

\section{Author Contributions}

Conception and design: Sheehan. Acquisition of data: Cordeiro. Analysis and interpretation of data: Sheehan, Cordeiro, Xu. Drafting the article: Cordeiro, Vance. Critically revising the article: all authors. Reviewed submitted version of manuscript: Sheehan, Cordeiro, Xu, Mehta, Ding, Kano, Sisterson, Yang, Kondziolka, Lunsford, Mathieu, Barnett, Chiang, J Lee, Sneed, Su, CC Lee, Krsek, Liscak, Nabeel, El-Shehaby, Abdel Karim, Reda, Martínez-Moreno, Martinez-Alvarez, Blas, Grills, KC Lee, Kosak, Cifarelli, Katsevman. Approved the final version of the manuscript on behalf of all authors: Sheehan. Statistical analysis: Cordeiro, Xu. Study supervision: Sheehan.

\section{Supplemental Information}

\section{Previous Presentations}

The abstract of the manuscript was presented in oral form at the 2018 AANS Annual Meeting, April 28 to May 2, New Orleans, LA.

\section{Correspondence}

Jason P. Sheehan: University of Virginia Health System, Charlottesville, VA. jsheehan@virginia.edu. 